\title{
APROPRIAÇÃO MUSICAL: A ARTE DE OUVIR RAP ${ }^{1}$
}

\author{
Jaison Hinkel ${ }^{\star}$ \\ Kátia Maheirie
}

RESUMO. Esta pesquisa teve por objetivo investigar se há e como se processa a relação estética entre sujeitos ouvintes e a música Rap, no processo de apropriação musical. Partimos da perspectiva sócio-histórica, segundo a qual nas reflexões metodológicas propostas por Vigotski estiveram tecidas as ideias de Bakhtin, como também as contribuições de Sartre, em um movimento dialógico com alguns leitores que se fazem interlocutores destes autores. Realizamos entrevistas individuais e abertas com cinco jovens moradores de periferia da região de Blumenau - SC. As análises indicaram a apropriação musical dos sujeitos investigados como um complexo processo que envolve aspectos referentes às propriedades físico-perceptuais do objeto estético Rap e a biografia de cada sujeito/ouvinte. A apropriação musical se mostrou como um complexo processo de conversão do coletivo em singular, fenômeno que exige um lugar cocriador do sujeito-ouvinte que se apropria dos significados expressos nas músicas e produz, a partir destes, novas zonas de sentido.

Palavras-chave: Rap; psicologia; apropriação musical.

\section{MUSICAL APPROPRIATION: THE ART OF RAPLISTENING}

\begin{abstract}
The research focus the aesthetic relations between listeners and the Rap songs singers and authors by musical subjective appropriation flux. From a social-historical perspective, in which where the Vygotsky's methodological reflections are connected to proposals by Bakhtin and Sartre's thinking by a dialogic fashion with in listeners become also authors. It was used as methodological processes open and singular interviews with five young inhabitants from Blumenau/SC peripherical areas. The first results points that musical appropriation by subjects under observation is a thick process that interweave subjective physical-perceptual and biographical aspects of each one of them. The musical appropriation singular processes investigated gave rise to an understanding that confirms the historical-cultural thesis that states social conversion of collective symbolic artifacts into subjective ones by a participatory relational negotiation of new meanings and collaboration of zones of sense.
\end{abstract}

Key words: Rap; psychology; musical appropriation.

\section{APROPIACIÓN MUSICAL: EL ARTE DE OÍR RAP}

RESUMEN. Esta investigación busca conocer como si procesalarelación estética entre losoyentes y la música Rap, en curso de La apropiación musical. Desde una perspectiva socio-histórica, que intercambia las reflexiones metodológicas de Vygotski, elpensamiento de Bakhtin y Sartre, se busca el diálogo conalgunoslectores e interlocutores de estos autores. Llevamoscon entrevistas individuales y abiertascon cinco habitantes jóvenes de periferia de laregión de Blumenau/SC. Los análisishabían indicado laapropiación musical de losciudadanos investigados como procesocomplejo que implica el referir de aspectos al físico-perceptuales de las características del Rap y de labiografía de losoyentes. La apropiación musical si está demostrado como procesocomplejo de laconversión de lacolectivaenel singular, fenómeno que exige un lugar cocreadordeloyente que se apropia de los significados expresosen musicas y produce, de éstos, nuevas zonas de ladirección.

Palabras-clave: Rap; psicología; apropiación musical.

\footnotetext{
Apoio: Fundo de Apoio à Manutenção e ao Desenvolvimento da Educação Superior - FUMDES

Mestrado em Psicologia pela Universidade Federal de Santa Catarina, Brasil(2008). Professor Substituto da Fundação Universidade Regional de Blumenau, Brasil.

II Doutorado em Psicologia (Psicologia Social) pela Pontifícia Universidade Católica de São Paulo, Brasil(2001). Professor Associado da Universidade Federal de Santa Catarina, Brasil
} 
Nosso intuito é contribuir para a reflexão sobre o(s) modo(s) como os sujeitos podem se apropriar do Rap. Para tanto, tomamos a música Rap como uma forma de linguagem reflexivo-afetiva, um modo de sentir e pensar capaz de criar emoções e inventar linguagens (Maheirie, 2003), e a relação estética como um modo específico de relação com o mundo em que um sujeito concreto e singular se posiciona com determinado olhar diante de um objeto, possibilitando o descolamento da percepção imediata para a produção de complexas sínteses de significados e sentidos, num processo de implicação afetiva (Vázquez, 1999; Vigotski² 1970/1999, 1926/2003). A apropriação musical, por sua vez, é aqui entendida como um movimento de conversão do coletivo em singular que pressupõe um lugar cocriador do sujeitoouvinte, já que a arte, conforme Vigotski (1970/1999), participa do cotidiano das pessoas como uma mediação entre o coletivo e o singular, possibilitando tornar pessoal aquilo que era coletivo sem deixar de ser social.

A pesquisa foi desenvolvida mediante entrevistas individuais e abertas com cinco jovens moradores de periferia da região de Blumenau - SC, com as quais se buscou apreender os sentidos que osentrevistados produziram no processo de apropriação musical, questionando se há e como se processa a relação estética entre estes e o Rap. Ressaltamos que os nomes dos entrevistados citados neste artigo são fictícios.

As análises foram empreendidas a partir da perspectiva sócio-histórica, em que as reflexões metodológicas propostas por Vygotski (1982/1992, 1960/1995) estiveram tecidas com as ideias de Bakhtin $(1926,1998,2010)$ e as contribuições de Sartre (1959/1984) e em um movimento dialógico com alguns leitores que se fazem interlocutores destes autores $^{3}$ (Aguiar, 2006; González Rey, 2002; Maheirie, 2002, 2003, 2006; Zanella, 2005, 2006; entre outros).

Vygotski (1982/1992) nos permitiu conceber o movimento de análise como uma busca pela apreensão dos sentidos, não bastando apenas identificar as palavras expressas pelos sujeitos pesquisados, visto que é preciso compreender sua tendência afetivovolitiva, seus motivos e interesses, desejos e

2 Utilizamos duas formas de escrita para o nome deste autor (Vigotski/Vygotski), respeitando o idioma de edição da obra consultada.

3 Cientes das diferenças epistemológicas entre Bakhtin, Vygotski e Sartre, o que nos permitiu congregar seus pontos de vista na pesquisa foi a proximidade de suas concepções de sujeito e dos processos de produção de conhecimentos em Ciências Humanas como devir. necessidades, sentimentos e emoções. Bakhtin (2010) ofereceu subsídios para nossa investigação ao indicar a dialogicidade como dimensão fundamental para a produção de um conhecimento capaz de reconhecer o homem como sujeito produtor de discurso, e não apenas como simples objeto. Sartre (1959/1984), por sua vez, nos ajudou a capturar a totalização da história singular e coletiva dos entrevistados, efetuando a análise no sentido de compreender a singularidade vivida na universalidade, num movimento que parte da singularidade em direção à universalidade e retorna a singularidade, sempre numa perspectiva histórica.

\section{ANÁLISE}

Consideramos necessário investigar a forma e o conteúdo da música Rap sem estabelecer dicotomia entre os dois aspectos, procurando oferecer uma compreensão totalizadora deste gênero musical. Isto nos levou a reconhecer que "o objeto estético é físicoperceptual, e nele o sensível se acha organizado em uma forma que o torna significativo." (Vázquez, 1999, p. 121)

Esta concepção totalizadora do artefato cultural Rap nos foi apontada pelos entrevistados de diferentes modos. Jão, por exemplo, aprecia a "qualidade de todos os elementos [do Rap] juntos"; Piá acha "a letra mais importante, mas a base tem que acompanhar a letra, tem que ser do mesmo estilo"; Mix considera que "tem que ter letra, batida e melodia massa"; Sansão afirmou que procura "a mistura da música boa, da batida boa com uma letra que me interessa"; e Brown, por sua vez, apresentou uma perspectiva capaz de sintetizar as anteriores ao mencionar que " $o$ Rap é um corpo, o ritmo é o coração dele e a poesia é a alma, um completa o outro".

Os entrevistados apontaram que a contemplação estética do Rap exige que este seja tomado como um objeto estético estruturado "arquitetonicamente" (Bakhtin, 1998, 2010), pois fora da relação com o conteúdo a forma não pode ser esteticamente significativa. Para os entrevistados, a configuração estética do Rap se deu justamente na totalização constituída pelo texto musical, o ritmo, a melodia e o estilo de cantar do rapper, o que nos fez considerar o processo de apropriação musical como uma relação dialógica entre som, letra e contexto, fenômeno que possibilitou movimentos de (re)invenção biográfica dos entrevistados, como veremos adiante.

A partir da perspectiva dos entrevistados, pensamos o ritmo, a poesia, a melodia e o canto do rapper como uma unificação contraditória, pois, apesar de diferentes, eles constituem uma totalidade 
dialética: um contém o outro e não existe sem ele (no caso específico da canção). Podemos pensar essa relação, metaforicamente, como a existente entre as dimensões cognitiva e afetiva do psiquismo humano, já que, como demonstrou Vygotski (1982/1992), apesar de possuírem suas especificidades, essas dimensões estão interconectadas.

Apesar de constituírem uma unidade, a letra e a base musical se mostraram como elementos que possuem funções diferentes no processo de apropriação. A base musical se faz mediação para os entrevistados se relacionarem com a música que, a partir da culturalização da sensorialidade, passa a ser experimentada mediante afetações corporais proporcionadas pela dimensão físico-sonora da música. Isto nos permite compreender que "a arte musical reside, em primeiro lugar, no modo como a música me toca" (Maheirie, 2003, p. 151), já que, como diria Vigotski (1970/1999), a obra artística começa onde inicia o seu mínimo, o que ocorre na sua dimensão formal ${ }^{4}$.

Além de a sonoridade se constituir como objeto estético, possibilitando processos de significação pela culturalização de artefatos pela via sensacional, percebemos que as letras das músicas solicitam dos entrevistados uma negociação de significações, utilizando-se de processos psicológicos complexos. Isto converte a letra em um canal de interlocução privilegiado no processo de significação das canções de Rap, pois a partir dela os sujeitos conseguem explicitar e propor complexas produções de sentidos. Deste ponto de vista, o acesso à forma e conteúdo da música Rap "é uma entrada no mundo dos símbolos pela porta do sentimento comum engendrado pelas combinações harmônicas e rítmicas." (Seca, 2004, p. 15)

Apesar de não estabelecermos dicotomia inconciliável entre as dimensões constitutivas (sonoridade ritmica e letra) da música Rap, reconhecemos o importante lugar do discurso verbal rapper nos processos das produções reflexivas, emotivas e imaginárias dos sujeitos neles enredados.

4 Apesar de concordarmos com estes autores, entendemos que é preciso tomar cuidado para não estabelecer dicotomia entre os processos (perceptivo, reflexivo, imaginário, etc.) ocorridos na apropriação musical, pois os processos psicológicos complexos não atuam de forma linear, mas dinâmica e dialética (Vygotski, 1960/1995). Assim, consideramos um erro pensar o processo de apropriação musical como um acontecimento dividido em etapas que se sucedam temporariamente, como se linearmente a música fosse tomada pelos órgãos do sentido, para posteriormente ser objeto de reflexão, podendo produzir alterações emocionais e gerar produções imaginárias.
Constatamos como fundamental o enredo na apropriação musical do Rap, uma vez que incorpora narrativas de histórias ocorridas no contexto das periferias urbanas. Alguns autores já haviam sinalizado o importante lugar ocupado pelas narrativas na música Rap, uma vez que é por meio delas que os rappers manifestam suas angústias, medos, inquietações, anseios, etc. (Scandiucci, 2006; Souza, 2009; Souza, Fialho \& Araldi, 2008; Tella, 1999, dentre outros). Esta constatação nos permitiu compreender a razão de os entrevistados decorarem as letras para cantá-las junto com os rappers.

Frith (1987) considera a música uma possibilidade para o sujeito compreender a si mesmo, ajudando-o a responder a questões de identidade singular e coletiva e produzindo simultaneamente sua autodefinição pessoal e seu lugar na sociedade. Neste sentido, cantar junto com um rapper não deve significar exclusivamente que o ouvinte quer ser ele, mas sim, que este identifica como sua também aprodução discursiva do rapper, o que pode lhe possibilitar complexificar sua existência a partir do processo de apropriação musical (Frith, 1987; Seca, 2004).

Seca destaca a possibilidade de o Rap não apenas falar sobre aspectos políticos e sociais, mas também sobre a vida e os sentimentos experimentados no cotidiano (2004). É justamente esta dialética entre o social e o singular que levou Vigotski (1970/1999) a considerar a arte como “(...) uma técnica social do sentimento, um instrumento da sociedade através do qual incorpora ao ciclo da vida social os aspectos mais íntimos e pessoais do nosso ser" (p. 315). Neste sentido, a alteridade se configura como dimensão social subjetivada nas relações das pessoas com a arte, já que, como disse Vigotski (1970/1999, p. 315), “a arte é o social em nós, e, se o seu efeito se processa em um indivíduo isolado, isto não significa, de maneira nenhuma, que as suas raízes e essência sejam individuais."

A partir da psicologia sócio-histórica, entendemos a relação estética como uma relação dialética entre sujeito e objeto, considerando que ambos possuem dimensões constituídas tanto pelo singular quanto pelo social. O sentimento social que é oportunizado pela vivência estética é constitutivo do próprio objeto estético, pois, se desconectada de suas origens sociais, a relação estética existe apenas como potencialidade (Vázquez, 1999).

Esta interface do social com o singular se mostrou de diferentes formas nas falas dos entrevistados, indicando especificidades na maneira como cada um se apropriou do Rap. A partir do método progressivoregressivo proposto por Sartre (1959/1984, p. 176), 
que aponta para “... um vaivém enriquecedor entre o objeto (que contém toda a época como significações hierarquizadas) e sua época (que contém o objeto na sua totalização)", percebemos que o processo de apropriação musical dos entrevistados revelou o estabelecimento de tensas relações entre estes e a cidade onde residem. Progressivamente, pudemos ver a história singular de cada sujeito investigado, a maneira como cada um tomou contato com este gênero musical e o fez elemento constitutivo de diferentes esferas de sua vida (lazer, sociabilidade, crítica social, afirmação de si, etc.). Regressivamente, consideramos a cidade de colonização germânica na qual estão inseridos estes sujeitos, atentando para a forte marca ainda presente nos dias atuais das tradições e dos costumes de seus colonizadores, considerando esta cidade inserida no atual contexto de globalização. Assim, a Blumenau germânica e rica apareceu nas falas dos entrevistados, em contraposição ao contexto miscigenado e pobre vivenciado por eles cotidianamente, o que nos permitiu considerar que os entrevistados tomaram a música como uma forma de (re)apropriação da cidade.

Ao ressignificarem a si mesmos e o contexto histórico-cultural no qual se encontram imersos, através da apropriação musical do Rap, a cidade de Blumenau apresenta-se aos sujeitos pesquisado como um lugar que possibilita contraditoriamente sua exclusão e inclusão (Sawaia, 1995). O Rap, neste sentido, oportuniza o questionamento dos valores eurocentrados que circulam em Blumenau e a colaboração negociada de novas significações interculturais.

$\mathrm{O}$ que se disse acima pôde ser constatado nos depoimentos de jovens afro-descendentes investigados pela pesquisa que tomaram o Rap como importante ferramenta para sua constituição identitária, promovendo a elevação de sua autoestima ou "autovalorização" (Brown) e o "amor pelo negro" (Sansão), empoderando seu protagonismo cidadão.

Devemos ressaltar que a identidade é concebida neste artigo de forma dialética e compreendida como um processo aberto e inacabado de totalizações em curso (Maheirie, 2002), que contempla movimentos de igualar-se e diferenciar-se nas relações com o outro.

A questão étnica e a condição social são fatores constitutivos da identidade rapper (Guasco, 2001; Lindolfo Filho, 2007). A aproximação de significados entre a identidade étnica e a condição social pode ser observada nas falas de Piá, Jão e Mix, sujeitos investigados não afro-descendentes, quando afirmam a existência dos estigmas de ser "pobre", "drogado" e "bandido" como atributos dos que se apropriam deste gênero musical, o que merece ser discutido a partir do "sentir-se menos gente" (Sawaia, 2010) na perspectiva da dialética exclusão/inclusão social.

As falas dos entrevistados apontam a alteridade como dimensão imprescindível das relações entre o sujeito e a música Rap, e o importante papel do imaginário nesta relação como constitutivo da apropriação estética (Vigotski, 1970/1999). O imaginário se revela como condição necessária para a ocorrência da relação estética, uma vez que esta se configura como uma ação que requer certo descolamento da realidade concreta, a qual é complexificada por uma forma de percepção que busca ir além dela para realizar densos processos de significação. Assim, pudemos perceber que é pela entrada no imaginário que o sujeito consegue transcender sua perspectiva pessoal para se relacionar com a alteridade, apropriando-se desta, concordando, refutando, complementando - enfim, (re)inventando os discursos que circulam socialmente. Vázquez (1999) nos ajudou a compreender esta questão ao considerar que o objeto estético, para se configurar como tal, necessita do olhar humano, pois o que caracteriza um quadro não está apenas no espaço físico delimitado de sua moldura, mas também no espaço criado pelo artista e cocriado pelo espectador.

A importância da narrativa para o Rap nos fez perceber a importância da imaginação no processo de apropriação musical, a tal ponto de considerarmos o Rap como uma espécie de "cinema sonoro". Os entrevistados nos apontaram isto ao caracterizarem os enunciados rappers como produções intensamente ricas em detalhes descritivos, o que lhes possibilitava vivenciarem as canções, como se estivessem imersos nelas. Tal fenômeno pôde ser constatado, por exemplo, quando Piá informa que "imagina a situação da vida do cara” a partir das letras das músicas. Piá, deste modo, recorre ao imaginário para produzir zonas de sentido a partir das narrativas de outros jovens que vivem em contextos de exclusão, recuperando experiências de sua própria vida que se aproximavam das descritas pelos rappers.

Os relatos de Mix também nos ajudaram a compreender a função desempenhada pelo imaginário no processo de apropriação musical ao considerá-lo como uma ação que permite ao ouvinte "imaginar ali a cena acontecendo" e se relacionar com o objeto estético a partir de uma postura empática. Considerando as contribuições de Bakhtin (2010), entendemos que tal acontecimento tem sua importância justamente porque é este movimento de aproximação, seguido de um afastamento, que oferece a possibilidade do sujeito estabelecer uma relação estética. Este complexo processo dialético de 
aproximação-distanciamento que ocorre mediante a imaginação nos processos de apreciação estética pode ser constatado a partir da seguinte fala de Jão:

\begin{abstract}
"Tem um som que fala de um cara que morreu num assalto, tá ligado? Tem umas paradas assim, tem um som que é triste, tipo assim, uma mina que no primeiro dia de trampo foi estuprada, tá ligado? Um cara que queria ser jogador de futebol e o avô ajudava, daí o cara acabou matando o avô pelo crack. Tipo as histórias assim que, pô, aquele som tu escuta ali que tu sai abalado, entende? Tu já "pô, esse mundo é cruel, né velho?". Acho que ele é cruel e fascinante, entende?"
\end{abstract}

O entrevistado revela que tomou as narrativas do Rap como mediação para sua produção imaginária. Apesar de se colocar numa postura de empatia em relação ao discurso rapper, Jão demonstra que realizou seu "excedente de visão" (Bakhtin, 2010) e ocupou uma perspectiva singular que o excede, o que lhe possibilitou considerar que o mundo não é apenas "cruel", mas também "fascinante".

A imaginação a partir da alteridade se mostrou como componente imprescindível para que os entrevistados pudessem estabelecer uma relação estética com o Rap que transcende suas perspectivas pessoais, na medida em que demonstram realizar movimentos que partem da posição singular ocupada por cada um em direção à alteridade para, em seguida, retornarem a ela transformados por aquela. $\mathrm{O}$ mesmo ocorre com Mix, que, por exemplo, mediado pelo discurso rapper, toma uma posição exotópica (Bakhtin, 2010) sobre si e passa a perceber sua vida com outros olhos, refletindo sobre a complexidade constituinte de seu viver e do de outros jovens de periferia, enxergando, como ele disse, "um mundo diferente que não conhecia”. Tal fenômeno tem sua importância por proporcionar ao entrevistado a possibilidade de (re)configurar suas formas de sentir, pensar e agir, pois, a partir de seu processo de apropriação musical, ele transcende sua perspectiva pessoal em direção à alteridade, lançando-se no imaginário e recuperando sua vida de um modo "diferente", enriquecido.

Este complexo movimento dos entrevistados de vai-e-vem da arte para a vida e vice-versa indica que “... o imaginário não é a antítese da realidade, senão que esta, marcada pela subjetividade humana, o engloba e lhe confere um lugar de destaque nos processos psicológicos mais complexos, como por exemplo, os processos de criação." (Maheirie, 2006, p. 150).
As formas como os entrevistados realizaram suas produções imaginárias em meio ao processo de apropriação musical podem ser pensadas a partir das contribuições de Vigotski (1930/2009), que concebeu quatro tipos de relação entre a imaginação e a realidade.

A primeira forma de vinculação apontada por esse autor considera que a imaginação desenvolve-se com base nas experiências concretas vividas pelo sujeito. Isto pôde ser percebido em vários momentos das falas dos entrevistados, como, por exemplo, quando afirmam que o Rap "fala a real, fala da realidade" (Brown, Jão, Piá, Mix e Sansão); "canta o sofrimento que a maioria passou" (Jão); "canta uma parada que pode tá acontecendo contigo" (Piá). É neste sentido que entendemos as vozes dos entrevistados como uníssonas na perspectiva de Maheirie (2003), que considera a música consequência de um complexo processo de criação que deve ser compreendido como um produto histórico-social por meio do qual sons são transformados numa objetividade subjetivada, como negação dialética do determinismo de um contexto.

O segundo modo de relação entre imaginação e realidade apontado por Vigotski sinaliza o enriquecimento que a produção imaginária pode propiciar à experiência humana, o que fica evidente nos momentos em que os entrevistados tomam os discursos dos rappers como mediação para uma postura reflexivo-crítica acerca de si e de seu contexto social. Assim, a produção imaginária realizada pelos entrevistados lhes possibilita organizar e elaborar seus pensamentos e sentimentos a partir das histórias dos personagens dos Rap's:

"Ali canta qual é que é, e o cara vai se ligando" (Mix); "o Rap trouxe pra mim, sei lá, mais humildade. Me fez enxergar um mundo diferente que eu não conhecia" (Mix); "eu sou o que eu sou pelo Rap, o Rap me deu muita instrução, me ensinou muita coisa" (Sansão); "O Rap faz pensar a real" (Piá).

A terceira forma identificada por Vigotski (1930/2009) se refere ao enlace emocional, fenômeno que se mostra tanto na participação exercida pela afetividade na construção de imagens, quanto na transmutação afetiva que o sujeito pode experimentar a partir da produção imagética. Aqui poderíamos recordar inúmeros momentos das entrevistas, seja quando os sujeitos indicaram a afetação proporcionada pelos discursos rappers, fazendo desencadear neles mesmos intensas emoções ("mexe"; "cutuca"; "arrepia"; "faz chorar"; "coração disparado"; 
"medo"; etc.), seja quando acenam para a possibilidade da transmutação afetiva, penetrando no mundo imaginário e modificando suas perspectivas de vida :"tu tá meio down e escuta aquele som 'levanta a cabeça guerreiro, é o seguinte', aquilo lá cutuca a tua autoestima”(Brown); "eu ouvia Racionais todo dia de manhã pra já sair de casa com a cara lavada, tipo pra animar"(Jão); "sentimento de revolta e a autoestima vem junto”(Sansão).

Por fim, o autor russo aponta para um vínculo entre imaginação e realidade que se refere à criação, ação que exige uma objetivação do que fora previamente imaginado. Apesar de não ser uma decorrência direta da experiência estética, a objetivação das produções imaginárias pode ser percebida nas próprias vidas dos entrevistados, os quais realizaram objetivações em seus modos de ser (sentir, pensar e agir). Brown nos ajudou a pensar isto ao afirmar que por meio do Rap passou a se "envolver mais com a Associação de Moradores”. Sansão optou pela atividade profissional de cabeleireiro afro, visualizada como uma forma de objetivar o "amor pelo negro" e de "espalhar a cultura afro".

Aqui é importante considerar que, como alertou Vigotski (1930/2009), não há passagem linear, direta, do imaginário para a criação, mas um complexo processo de transformação de uma dimensão em outra, fenômeno denominado pelo autor de "as torturas da criação". Da mesma maneira, pudemos perceber em nossa investigação que a apropriação do Rap não aconteceu passivamente, já que exigiu intensa atividade psíquica por parte dos ouvintes, os quais realizaram complexos processos de produção de sentidos a partir das obras musicais. Parafraseando o autor russo, consideramos que os entrevistados nos mostraram "as torturas da apropriação", indicando que a partir da apreciação do Rap eles realizaram a segunda síntese criativa (Vigotski, 1926/2003), a qual se configurou em complexos processos de subjetivação e objetivação.

A discussão que realizamos sobre a alteridade e o imaginário como dimensões constituintes da relação estética nos remete ao conceito de exotopia (Bakhtin, 2010) como condição e possibilidade para as transmutações afetivas vividas pelos entrevistados. A partir da perspectiva bakhtiniana (2010), entendemos que o sujeito só consegue se relacionar esteticamente com um objeto na medida em que exerça em relação a este o seu "excedente de visão". Neste sentido, na relação estética, o sujeito se vê numa posição de fronteira entre ele mesmo e os outros, realizando um estranhamento de si e do outro e permitindo-se tomar novas perspectivas a partir de sua relação com a totalidade do objeto. Este complexo movimento possibilita ao sujeito um distanciamento da realidade concreta para imergir numa realidade estética, circunscrita ao imaginário e à afetividade (Vigotski, 1970/1999), fenômeno constatado em diversos momentos das entrevistas. A partir das falas de Brown, por exemplo, temos um indicativo da posição exotópica assumida pelo entrevistado nos momentos em que ele revela que por meio do Rap passou a tomar a si e a sociedade como objeto de reflexão afetiva e crítica.

Daí quando eu ouvi aquele outro som do GOG, "A verdadeira malandragem", eu achava que era o bam, bam, bam na rua e pá, o gurizão, o malucão, mas ele dizia: "não, a verdadeira malandragem não é isso aí não, cara, a verdadeira malandragem é estudar, é dar uma força pra coroa”. Aí ali mudou minha vida, tá ligado? Ali eu disse "pô, é verdade, NE, cara? Vamos aí, vamos aî". Sansão:

Outro exemplo é o seguinte comentário de

"Eu comecei a ouvir o Rap como música, aí eu fui vendo a minha vida toda como eu vivia, tipo perseguição na escola, as meninas não queriam ficar comigo, vê os caras tudo com mina e eu não. Pra mim era normal, né? Era tido como normal, o negro é pobre e bababá, isso é cultural já, né? Daí o Rap começou a questionar isso pra mim, me fez questionar isso, prestar atenção nisso".

Podemos ver que a partir da apropriação do Rap Sansão passou a olhar para si e a questionar suas experiências de vida e os significados/sentidos nela produzidos. Sua forma de objetivação como cabeleireiro, ao realizar penteados "afro" em moradores de uma cidade colonizada por alemães, também é uma ação indicativa de sua posição exotópica, no sentido de que permitiu ao entrevistado e as pessoas nas quais realiza os penteados tomar um excedente de visão e colocar-se como outro para si. Da mesma maneira, as entrevistas de Jão e Mix indicaram a tomada de uma postura exotópica ao apontarem o Rap como importante mediação reflexiva sobre a complexidade constituinte do viver singular de cada entrevistado e da sociedade à qual pertencem. Neste prisma, a produção psíquica realizada pelos entrevistados a partir do processo de apropriação musical culminou em complexas transmutações em suas formas de sentir, pensar e agir, acontecimento caracterizado por um movimento de distanciamento da 
perspectiva pessoal em direção à alteridade, o que possibilitou que cada um deles retornasse enriquecido para sua perspectiva singular. A importância desta postura exotópica para o debate acerca da relação estética no processo de apropriação musical decorre justamente do fato de que, "ao distanciar-se de certa realidade e 'tirar-lhe essa marca de familiaridade que hoje os mantém ao alcance da mão', o sujeito recupera sua liberdade, seu poder reflexivo e crítico, sua capacidade de aceitar uma nova realidade" (Vázquez, 1999, p. 152).

Importante destacar que este distanciamento que o sujeito realiza lhe promove intensas transmutações afetivas, o que pode ser observado naseguinte fala de Brown:

"É a música de autoestima, tá ligado? Tipo, tu tá meio down e escuta aquele som "levanta a cabeça guerreiro, é o seguinte", aquilo lá cutuca a tua autoestima e tu pensa: "é verdade, não é bem assim não, vamos aí", tá ligado? Sempre no protesto de autoestima, né cara? Aumentando a autoestima pra protestar".

Esta fala pode ser complementada por outras dos demais entrevistados para se referir à superação de seus sentimentos a partir de suas relações com o Rap. Jão, por exemplo, revelou que "quanto mais sofrimento aí mesmo que o Rap bate", porque, para ele, este gênero musical é "estimulante", "mexe", "cutuca", "abre o sorriso na cara", "encanta", "anima", permite-lhe "sair de cara lavada". Mix também nos ajuda a entender a vivência catártica, considerando que a afetação experimentada pelo entrevistado no contato com o Rap permeou todo o seu discurso e pode ser sintetizada com a seguinte frase: "No Rap tem que rolar, assim como em todos os sons, tem que dizer alguma coisa pro cara, e é por isso que arrepia. Tem som que arrepia o cara porque fala pra caramba”. Tal fenômeno pôde também ser constatado quando Mix afirma que "tem que ter sentimento pela comunidade" e "passar respeito $e$ autoestima”.

As falas dos entrevistados apontaram para uma imensa gama de sentimentos opostos experimentados no processo de apropriação musical, fenômeno que lhes possibilita "levantar a cabeça" (Brown) diante de situações de sofrimento e "sair de cara lavada" (Jão). A complexidade afetiva constituinte da catarse (Vigotski, 1970/1999) pode ser também observada na fala de Sansão:

"Quando eu ouço um Rap, quando eu ouço MV Bill, ao mesmo tempo em que eu acredito que essa vinda já era, que talvez numa segunda vinda a humanidade tenha um jeito, uma salvação, uma coisa assim, tá ligado? $O$ Rap ele também me diz que eu não posso parar... Sentimento de revolta e a autoestima vem junto, tá ligado? Cada obstáculo que o Rap demonstra ele mostra como um obstáculo, mas ele me faz entender como um desafio também, algo a ser superado, que me dê mais força pra continuar nessa caminhada, ensinar isso pro meu filho. É isso, tenho sentimento de revolta, de amor, raiva, tem tristeza, tem alegria, vitória, vejo derrota, mas ele me ensina que eu tenho que ir atrás da vitória".

Pode-se constatar nas falas dos entrevistados que é por meio da contradição afetiva que todas estas complexas vivências são experimentadas, configurando a catarse como uma espécie de "jogo de sentimentos" (Vigotski, 1970/1999, p. 257), haja vista que "a contradição, a repulsa interna, a superação, a vitória; todos eles são componentes necessários do ato estético." (Vigotski, 1926/2003, p. 235). Deste modo, a relação estética com o Rap não se reduz a mera identificação e/ou descarga de emoções a partir dos discursos rappers, uma vez que, conforme o autor, a catarse não se caracteriza pela simples expressão de sentimentos que contagiam o ouvinte, mas por um curto-circuito que gera complexas transmutações em seus sentimentos. Isto significa que "a arte suspende o homem de sua vida cotidiana, demonstrando que ele é mais rico que sua vida. A arte não distrai nossos sentimentos ou nos contagia, mas sim nos força a vencer o sentimento." (Sawaia, 2006, p. 90).

Maheirie (2003) também contribui para a compreensão da complexa relação que os entrevistados estabeleceram com o Rap ao considerar que a afetividade é uma questão central na relação do sujeito com a música, pois "traz uma dimensão que se objetiva no corpo, outra que implica numa seleção de pensamentos, e uma terceira que se constitui em imagens, sem as quais não constituiríamos um mundo 'mágico ." (p. 150). Assim, a afetividade não é apenas uma forma de ligação/identificação dos entrevistados com o Rap, mas, ainda segundo Maheirie (2006), é o que orienta a maior parte de nossas ações no mundo e abarca as formas perceptiva, reflexiva e imaginativa, configurando-se como dimensão unificadora de diferentes aspectos do psiquismo do sujeito.

A afetividade assim considerada permitiu-nos constatar que os afetos experimentados pelos entrevistados revelam que eles estão por inteiro no processo de apropriação musical, uma vez que a contemplação lhes permite relacionar-se 
sensivelmente com um objeto para produzir complexas significações que traduzem como o sujeito sente, pensa e padece (Vázquez, 1999). As vivências afetivas experimentadas pelos entrevistados constituem uma dimensão extremamente importante no processo de apropriação do Rap, pois a experiência estética exige do sujeito um afastamento da realidade concreta, para, a partir desta, inserir-se no campo do imaginário e dos afetos (Vigotski, 1970/1999). É este acontecimento que possibilita ao sujeito vivenciar emoções de ordem estéticas, as quais são denominadas por Vigotski de "emoções inteligentes" (1970/1999, p. 267), por serem constituídas e desencadeadas animicamente.

Nosso entendimento é que a relação estética configura “... uma experiência vital e sensível, onde se perde a distância entre imaginação e realidade, e onde se acede a um mundo de sentido por via lúdica." (Barrios, 1999, p. 69). Ademais, concebemos que os entrevistados, por meio do Rap, adentraram em contextos de exclusão de uma forma lúdica, transformando o sofrimento em lazer, sociabilidade, afirmação de si, crítica social - enfim, ressignificando os discursos circunscritos à periferia e colocando em jogo uma disputa de sentidos sobre a vida neste contexto.

Isto nos fez entender o Rap não apenas como instrumento de reflexão crítica, mas, sobretudo, de superação afetiva. É nesta perspectiva que tomamos o conceito de potência de ação para problematizar as transmutações vivenciadas pelos entrevistados, considerando que este realça o papel positivo da afetividade como elemento constitutivo do pensar e do agir (Sawaia, 2010), e a cena para o enlace entre as dimensões afetiva, cognitiva e sociorrelacional humana. Os depoimentos dos entrevistados nos levaram a concordar com Sawaia (2009) em que é na interface destas dimensões que o processo de apropriação musical pode ampliar a potência de ação dos sujeitos, possibilitando-lhes lutar pela preservação da própria existência. Tal potencialidade se realiza de acordo com o modo como cada um deles afeta e é afetado pelos outros, simultaneamente na configuração da ação, do significado e da emoção coletivos e individuais (Sawaia, 2010).

O Rap apresentou-se como mediação para o aumento da potência de ação dos entrevistados, os quais acenaram para este gênero musical como um fenômeno que une as dimensões ética e estética do humano, o que pode ser pensado a partir das proposições de Vigotski (1926/2003) acerca da educação estética. Para o autor, a educação estética não visa embelezar a vida, mas reelaborá-la criativamente, ampliando a experiência humana singular a partir do aproveitamento da experiência historicamente acumulada pela humanidade para ampliá-la e enriquecê-la com novas criações.

Neste sentido, os entrevistados utilizam o Rap para recriar criativamente a realidade e ampliar suas experiências, o que pode ser constatado na falas de Brown, que caracteriza este gênero musical como "protesto bonito, inteligente", "aumentando a autoestima pra protestar". Podemos tomar como exemplar deste processo de empoderamento e protagonismo através da apropriação musical do Rap a atuação de Sansão como cabeleireiro afro para o enfrentamento da desqualificação étnica e social vivenciada no movimento afirmativo de sua afrodescendência como positividade.

\section{ÚLTIMAS CONSIDERAÇÕES}

A pesquisa realizada sinaliza o entendimento da apropriação musical como um complexo processo que envolve aspectos referentes às propriedades físicoperceptuais do objeto estético Rap e a biografia de cada sujeito-ouvinte. A forma (rítmico-sonora) e o conteúdo (letra e atitude) do Rap apresentam-se como contradição que encontra superação em complexas produções de sentido. Elas se mostraram como unidade contraditória, onde a forma foi tomada como uma possibilidade de acesso ao mundo por uma via sensível, e a letra como um canal de acesso privilegiado ao universo de significação da canção, pois a partir dela foram realizadas complexas produções de sentido. A imaginação, a partir da alteridade, também se revelou imprescindível para que os entrevistados pudessem estabelecer uma relação estética com o Rap e transcender suas perspectivas pessoais, porquanto realizaram movimentos que partiam da posição singular ocupada por cada um em direção à alteridade para, em seguida, retornarem enriquecidos para si mesmos.

$\mathrm{O}$ enlace entre as dimensões ética e estética ocupou espaço de destaque na discussão dos dados obtidos por privilegiar o lugar ocupado pela transmutação afetiva, culminada em catarse, nos movimentos de (re)invenção biográficados sujeitos pesquisados.

O Rap apresentou-se como "trilha sonora da vida" dos entrevistados, como nos revelou Brown, ou seja, como uma espécie de "organizador do comportamento", como diria Vigotski (1970/1999, 1926/2003). Deste modo, a arte não busca a repetição de qualquer ação real, mas a sua superação, de maneira que uma obra de arte vivenciada 
esteticamente cria um estado muito sensível para ações posteriores e pode ampliar nossa opinião sobre as coisas, fazer-nos observar os fenômenos com outros olhos, generalizar e reunir fatos por vezes dispersos (Vigotski, 1970/1999, 1926/2003).

Em resumo, a apropriação musical se mostra como um complexo processo de conversão do coletivo em singular, fenômeno que exige um lugar cocriador do sujeito-ouvinte que se apropria dos significados expressos nas músicas e, a partir destes, produz novas zonas de sentido.

Por fim, é preciso dizer que se buscou trilhar com esta pesquisa possibilidades de abordar a apropriação musical do Rap a partir de um olhar capaz de considerar as dimensões do lazer, da sociabilidade, da manifestação cultural, das críticas sociais, econômicas e políticas, na desconstrução e reconstrução de identidades, tanto no singular, quanto no coletivo. Tal perspectiva permite superar a concepção unilateral que qualifica a música, especialmente o Rap, ora como discurso político, ora como expressão artística, adotando-se uma perspectiva que tenta ir além, e contemplar uma importante interface entre arte e política. Neste sentido, Vigotski nos ajuda a dialetizar esta problemática, particularmente quando adverte que "se os poemas sobre a tristeza tivessem apenas a finalidade de nos comunicar tristeza, isso seria muito triste para a arte." (1926/2003, p. 232).

Nosso entendimento é que o protesto no Rap não tem como intenção única e exclusiva denunciar. Conforme afirma Brown em trechos de seu depoimento, ele pode ser "bonito", "inteligente" e auxiliar os sujeitos-ouvintes a reelaborarem criativamente seus sentimentos, pensamentos e vivências, caracterizando o que ele chamou de "protesto de autoestima".

Os resultados até aqui obtidos permitem considerar que o sujeito, a partir de uma postura estética, pode estar apontando para um caráter transgressor de processos de exclusão/inclusão social, ao mesmo tempo em que se reinventa em horizontes mais largos de emancipação.

\section{REFERÊNCIAS}

Aguiar, W. M. J. (2006). A pesquisa junto a professores: fundamentos teóricos e metodológicos. In W. M. J. A.Aguiar (Org.), Sentidos e significados do professor na perspectiva sócio-histórica: relatos de pesquisa (pp.11-22). São Paulo: Casa do Psicólogo.

Bakhtin, M. M. (1998). O problema do conteúdo, do material e da forma na criação literária. In M. M. Bakhtin. Questões de literatura e de estética: a teoria do romance(4a ed., pp. 13-70). São Paulo: Unesp.
Bakhtin, M. M. (2010). Estética da criação verbal (5a ed.). São Paulo: Martins Fontes.

Bakhtin. M. M. (1926). Discurso na vida e na arte: sobre poética sociológica. (C. A. Faraco, C. Tezza, Trad.). Circulação restrita.

Barrios, J. L. (1999). Cuerpo y percepción: subjetividad y escritura de la historia del arte. In L. Enríquez (Org.). (In)Disciplinas: Estética e história del arte en el cruce de los discursos (pp.69-91). México: Instituto de investigaçãoestética.

Frith, S. (1987).Toard in aesthetic of popular music.In S. McLary., \& R. Leppert (Orgs.), Music and Society: the politic of composicion, performance and recepcion. Cambrige: CambrigeUniversity Press.

González Rey, F. (2002). Pesquisa qualitativa: caminhos e desafios. São Paulo: Pioneira Thomson Learning.

Guasco, P. P. (2001). Num país chamado periferia: identidade e representação da realidade entre os rappers de São Paulo. Dissertação de Mestrado não publicada, Programa de PósGraduação em Antropologia Social, Universidade de São Paulo, São Paulo.

Lindolfo Filho, J. (2007). Hip Hopper: tribus urbanas, metrópoles e controle social. In J. M. B. Pais., \& M. S. Leila.Tribos urbanas: produção artística e identidades (pp. 127-150). São Paulo: Annablume.

Maheirie, K. (2002). Constituição do sujeito, subjetividade e identidade. Revista Interações, 7(13), 31-44.

Maheirie, K. (2003). Processo de criação no fazer musical: uma objetivação da subjetividade, a partir dos trabalhos de Sartre e Vygotsky. Psicologia em Estudo, 8(2), 147-153.

Maheirie, K. (2006). Subjetividade, imaginação e temporalidade: a atividade criadora em objetivações discursivas. In S. Z. Da Ros., A. V. Zanella., \& K. Maheirie (Orgs.), Relações Estéticas, atividade criadora e imaginação: sujeitos e (em) experiência (pp. 145-155). Florianópolis: NUP/CED/UFSC.

Sartre, J. P. (1984). Questão de método. In J. P. Sartre. Os Pensadores (pp. 109-191). São Paulo: Abril Cultural. (Trabalho original publicado em 1959).

Sawaia B. B. (1995). O calor do lugar: Segregação urbana e identidade. São Paulo em Perspectiva, São Paulo, 9(2), 20-24.

Sawaia, B. B. (2006). Introduzindo a afetividade na reflexão sobre estética, imaginação e constituição do sujeito. In S. Z.Da Ros., A. V. Zanella., \&K. Maheirie (Orgs.), Relações Estéticas, atividade criadora e imaginação: sujeitos e (em) experiência (pp. 85-94). Florianópolis: NUP/CED/UFSC.

Sawaia, B. B. (2009). Psicologia e desigualdade social: uma reflexão sobre liberdade e transformação social. Psicologia e Sociedade, 21(3), 364-372.

Sawaia, B. B. (2010). O sofrimento ético-político como categoria de análise da dialética exclusão/inclusão. In B. B. Sawaia (Org.), As artimanhas da exclusão: Análise psicossocial e ética da desigualdade social (10a ed., pp. 97-118). Petrópolis: Vozes.

Scandiucci, G. (2006). Cultura hip hop: um lugar psíquico para a juventude negro-descendente das periferias de São Paulo. Imaginário, 12(12), 225-249.

Seca, J. M. (2004). Los músicos underground. Barcelona: Paidós. 
Souza, A. M. (2009). “A caminhada é longa ... e o chão tá liso!” O Movimento hip hop em Florianópolis e Lisboa. Tese de Doutorado não publicada, Programa de Pós-Graduação em Antropologia Social, Universidade Federal de Santa Catarina, Florianópolis.

Souza, J., Fialho, V. M., \& Araldi, J. (2008). Hip Hop: da rua para a escola (3a ed.). Porto Alegre: Sulina.

Tella, M. A. P. (1999). Memória e identidade. In E. N. Andrade (Org.), Rap e educação: rap é educação (pp. 55-63). São Paulo: Summus.

Vázquez, A. S. (1999). Convite à estética. Rio de Janeiro: Civilização Brasileira.

Vigotski, L. S. (1999). Psicologia da arte. São Paulo: Martins Fontes. (Original publicado em 1970).

Vigotski, L. S. (2003). Psicologia Pedagógica. Porto Alegre: Artmed. (Original publicado em 1926).

Vigotski, L. S. (2009). Imaginação e criaçãonainfância: ensaio psicológico: livro para profesores.São Paulo: Ática. (Original publicado em 1930).
Vygotski, L. S. (1992). Pensamiento y Palabra. In Obras Escogidas (Vol. 2, pp. 287-348). Madri: Visor. (Original publicado em 1982).

Vygotski, L. S. (1995). Problemas dell desarrollo de la psique. In Obras Escogidas (Vol. 3, pp. 97-120). Madrid: Visor. (Original publicado em 1960).

Zanella, A. V. (2005). Sujeito e alteridade. Psicologia e Sociedade, 17(2), 99-104.

Zanella, A. V. (2006). Pode até ser flor se flor parece a quem o diga: reflexões sobre Educação Estética e o processo de constituição do sujeito. In S. Z.Da Ros., A. V. Zanella., \& K. Maheirie (Orgs.), Relações Estéticas, atividade criadora e imaginação: sujeitos e (em) experiência (pp. 33-47). Florianópolis: NUP/CED/UFSC.

Recebido em 19/04/2010

Aceito em 20/10/2011
Endereço para correspondência:
Jaison Hinkel. Rua Marcial do Nascimento, 228, Bairro Bela Vista, CEP: 89100-000, Gaspar-SC, Brasil.E-mail: jaisonhinkel@yahoo.com.br. 